\title{
Antitumor activity of asukamycin, a secondary metabolite from the actinomycete bacterium Streptomyces nodosus subspecies asukaensis
}

\author{
PAUL R. SHIPLEY ${ }^{1}$, CAITLIN C.A. DONNELLY ${ }^{2}$, CUONG H. LE ${ }^{1}$, \\ ASHLEY D. BERNAUER ${ }^{2}$ and ANDIS KLEGERIS ${ }^{2}$ \\ Departments of ${ }^{1}$ Chemistry; ${ }^{2}$ Biology, Irving K. Barber School of Arts and Sciences, \\ University of British Columbia Okanagan, Kelowna, BC, V1V 1V7, Canada
}

Received June 3, 2009; Accepted July 23, 2009

DOI: 10.3892/ijmm_00000283

\begin{abstract}
Asukamycin, a manumycin-type metabolite, was isolated by a rapid and easily scalable purification scheme. Thus far, studies on the biological activity of asukamycin have been limited to its role as an antibacterial and antifungal agent. By using five different tumor cell lines we demonstrate antineoplastic activity of asukamycin. It inhibited cell growth at concentrations similar to other members of the manumycin family $\left(\mathrm{IC}_{50} 1-5 \mu \mathrm{M}\right)$. Cytotoxicity of asukamycin was accompanied by activation of caspases 8 and 3 and was diminished by SB 202190, a specific p38 mitogen-activated protein kinase (MAPK) inhibitor. These data, in combination with earlier observations showing its low in vivo toxicity, indicate that further studies on the potential antitumor activity of asukamycin are warranted.
\end{abstract}

\section{Introduction}

In recent years, intensive research has been focused on identification of new natural antitumor agents derived from various plants, marine organisms, animals and microorganisms. The manumycin-group metabolites are a small and distinct class of secondary metabolites produced by actinomycete bacteria. Most of the metabolites from this group inhibit the growth of Gram-positive bacteria, but are ineffective against Gram-negative bacteria (1). This group includes manumycin itself (Fig. 1A) as well as several other related molecules, all varying in the construction of the upper polyketide chain (Fig. 1). Thus this structural element is responsible for the variance in activities displayed by the family. Asukamycin is a manumycin-group metabolite that is produced by

Correspondence to: Dr Andis Klegeris, Department of Biology, Irving K. Barber School of Arts and Sciences, University of British Columbia Okanagan, 3333 University Way, Kelowna, BC V1V 1V7, Canada

E-mail: andis.klegeris@ubc.ca

Key words: asukamycin, antitumor agents, manumycin metabolites, leukemia, astrocytomas, cancer
Streptomyces nodosus subspecies asukaensis (Fig. 1B). In asukamycin the upper polyketide chain is primed by cyclohexane carboxylic acid and extended with three equivalents of acetate.

A number of different biological properties of manumycingroup metabolites have been reported. They include not only antibacterial activity but also other effects as diverse as antifungal, anticoccidial and insecticidal activity, inhibition of farnesyltransferase and interleukin $1 ß$ converting enzyme (ICE), prevention of atherosclerosis, regulation of IкB kinase signalling, as well as cytotoxic effects towards various tumor cells (1-4). The antitumor activity of this group of metabolites has been studied, for example, by using manumycins A-D, which are primarily produced by Streptomyces parvulus. They have shown cytotoxic effects against a variety of tumor cells including murine and human leukemia cells $(5,6)$ as well as human colon, thyroid, hepatic and ovarian cancer cells $(3,4,7-10)$. Only a very limited number of biological activities have been reported for asukamycin thus far. It has been shown to possess antibacterial, weak antifungal and anticoccidial properties (11).

In view of the structural similarity of asukamycin and various manumycins, we hypothesized that asukamycin, like some of the other manumycins, possesses antitumor activity. In order to test this hypothesis, we first developed a novel method of rapid isolation of asukamycin from bacterial cultures, which we subsequently used to obtain milligram quantities of the compound. We show that asukamycin is toxic against several human leukemia and astrocytoma cell lines. Furthermore, we demonstrate that, as with manumycins, the observed toxicity is dependent on the p38 mitogenactivated protein kinase (MAPK) pathway and is associated with activation of caspases 8 and 3 .

\section{Materials and methods}

Materials. Intracellular caspase activity detection kits were purchased from MBL International (Woburn, MA, USA). SB 202190, a highly selective, cell permeable inhibitor of p38 MAPK, the formazan dye 3-(4,5-dimethylthiazol-2-yl)-2,5diphenyl tetrazolium bromide (MTT), dimethyl sulfoxide (DMSO) and Bradford reagent were purchased from Sigma 


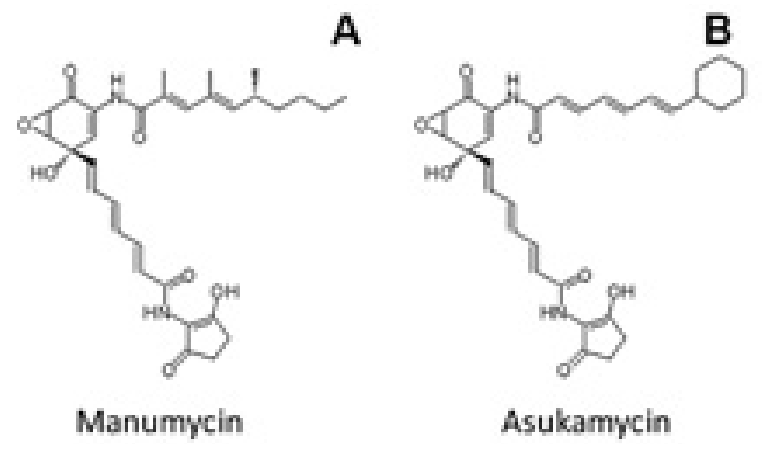

Figure 1. Chemical structures of manumycin (A) and asukamycin (B).

(St. Louis, MO, USA). Cell culture reagents were supplied by Thermo Scientific HyClone (Logan, UT, USA). Reagents used for bacterial growth and purification of asukamycin were from Fisher Scientific (Ottawa, ON, Canada) unless stated otherwise.

Growth of Streptomyces nodosus. Streptomyces nodosus subspecies asukaensis (Sno) cultures [American Type Culture Collection (ATCC) catalogue \#29757] were kindly provided by Dr Heinz G. Floss, University of Washington, Seattle, USA. Asukamycin production medium $(100 \mathrm{ml}$; glucose $20 \mathrm{~g} / \mathrm{l}$, peptone $5 \mathrm{~g} / \mathrm{l}, \mathrm{K}_{2} \mathrm{HPO}_{4} 0.25 \mathrm{~g} / \mathrm{l}, \mathrm{MgSO}_{4} 0.25 \mathrm{~g} / \mathrm{l}$, Hopwood trace elements solution $20 \mathrm{ml} / \mathrm{l}, \mathrm{pH} 7.0$ ) in a $500 \mathrm{ml}$ baffled Erlenmeyer flask was inoculated with $100 \mu 1$ of a Sno aerial mycelium stock (12). Three of these vegetative cultures were incubated in a New Brunswick Innova (Edison, NJ, USA) shaking incubator at $28^{\circ} \mathrm{C}, 200 \mathrm{rpm}$ for $48 \mathrm{~h}$. Aliquots of the cultures $(10 \mathrm{ml})$ were then used to inoculate each of twenty $500 \mathrm{ml}$ baffled Erlenmeyer flasks containing $100 \mathrm{ml}$ asukamycin production medium. These production cultures were incubated at $28^{\circ} \mathrm{C}, 200 \mathrm{rpm}$, for $72 \mathrm{~h}$ before harvesting.

Isolation of asukamycin. The production cultures were combined and the solids were separated by centrifugation at $16,000 \mathrm{x} g$ for $1 \mathrm{~h}$. The supernatant and pellets were extracted separately. The supernatant was extracted three times with an equal volume of ethyl acetate. The ethyl acetate fractions were combined, dried with an excess of anhydrous $\mathrm{MgSO}_{4}$, and the solvent was removed in vacuo.

Pellets were combined and suspended in a total of $200 \mathrm{ml}$ of acetone. The resulting suspension was separated by centrifugation at $16,000 \mathrm{x}$ g for $1 \mathrm{~h}$ and the acetone decanted off of the solids. The acetone was removed in vacuo, and the resulting paste extracted three times with an equal volume of ethyl acetate. The ethyl acetate fractions were combined, dried with an excess of anhydrous $\mathrm{MgSO}_{4}$, and the solvent was removed in vacuo.

The residue from the extractions of the supernatant and pellets were dissolved in a total volume of $10 \mathrm{ml}$ of methylene chloride and combined. Fine solids were then removed using a $0.45-\mu \mathrm{m}$ syringe filter. Hexane was added in $1 \mathrm{ml}$ aliquots to a final volume of $50 \mathrm{ml}$, causing the asukamycin to precipitate from solution. The asukamycin was collected on a Whatman \#3 filter then washed three times with water followed by three hexane washes. The asukamycin was liberated from the paper with acetonitrile, which was removed in vacuo resulting in the purified product. The above procedure produced up to $140 \mathrm{mg}$ of asukamycin per liter of the initial bacterial culture. Asukamycin was found to be stable for at least 3 weeks as a $20 \mathrm{mg} / \mathrm{ml}$ solution in DMSO at $-20^{\circ} \mathrm{C}$.

Determination of asukamycin purity and its quantification. Ultraviolet/visible (UV/Vis) spectroscopic analysis was performed using a Cary 100 double beam spectrophotometer with matched quartz 1-cm cuvettes. The quantity of asukamycin was determined by serial dilution in acetonitrile and Beer's law analysis using the literature $\lambda_{\max }$ at $313 \mathrm{~nm}(\varepsilon=49,400)(13)$.

Identity and purity of asukamycin were confirmed by separation on an Acquity Ultra Performance Liquid Chromatography coupled with a Micromass LCT Premier High Resolution Time of Flight Mass Spectrometry (UPLC/(ToF)MS) (Waters Inc., Milford, MA, USA). The purified asukamycin was dissolved in a 50:50 (v/v) solution of methanol in $0.1 \%$ aqueous trifluoroacetic acid (TFA) and separated on a Waters Acquity BEC C18 reversed phase UPLC column $(2.1 \times 100 \mathrm{~mm}, 1.7 \mu \mathrm{m}$ particle size $)$ using a gradient from $5 \%$ acetonitrile in $0.1 \%$ aqueous TFA to $95 \%$ acetonitrile in aqueous TFA over $10 \mathrm{~min}$ at $250 \mu \mathrm{l} / \mathrm{min}$. Asukamycin was eluted in $9.2 \mathrm{~min}$, with a minor contaminant eluting just before it at $8.8 \mathrm{~min}$. Comparison of the measured mass to the mass calculated using Beer's law was also used to confirm purity. The above analyses yielded a purity of $>85 \%$. High resolution time of flight mass spectrometry using positive mode electrospray ionization showed a molecular ion $\left(\mathrm{M}+\mathrm{H}^{+}\right)$ at $547.2441 \mathrm{~g} / \mathrm{mol}$ (calculated $547.2444 \mathrm{~g} / \mathrm{mol}$ ).

Nuclear magnetic resonance (NMR) spectrometry was performed using a Varian Mercury Plus spectrometer equipped with a gradient field capable probe operating at $400 \mathrm{MHz}$ for ${ }^{1} \mathrm{H}$. Proton spectra were acquired in chloroform- $d$ and compared with literature values (13).

Human cell cultures. The human myeloid leukemia THP-1, HL-60 and U-937 cell lines, as well as the human astrocytoma U-118 MG and U-87 MG cells, were obtained from the ATCC (Manassas, VA, USA). Cells were grown in Dulbecco's modified Eagle's medium-nutrient mixture F12 ham (DMEM-F12) supplemented with 10\% fetal bovine serum (FBS) and penicillin $(100 \mathrm{U} / \mathrm{ml}) /$ streptomycin $(100 \mu \mathrm{g} / \mathrm{ml})$.

Cytotoxicity assay. Cell growth inhibition was measured by using the MTT assay to estimate the relative number of viable cells (14). Human myeloid THP-1, HL-60 and U-937 cells were seeded into 24-well plates (BD Falcon, Mississauga, ON, Canada) at a concentration of $3 \times 10^{5}$ cells per well in $0.6 \mathrm{ml}$ of DMEM-F12 medium containing 5\% FBS. Human U-118 MG and U-87 MG astrocytoma cells were seeded at $1 \times 10^{5}$ cells per well in $0.4 \mathrm{ml}$ of culture medium and allowed to adhere for $24 \mathrm{~h}$ before asukamycin treatment was initiated. Various concentrations of asukamycin $(1-50 \mu \mathrm{M})$ or its vehicle solution (DMSO) were used. Concentration of DMSO in the cell culture medium did not exceed $0.5 \%$. After $24 \mathrm{~h}$ of incubation, the number of surviving cells was measured by the MTT assay as described before (15). This method is based on the ability of viable cells to convert the tetrazolium salt (MTT) to colored formazan. The viability of cells was determined by adding MTT to the cell cultures to reach a final concentration 


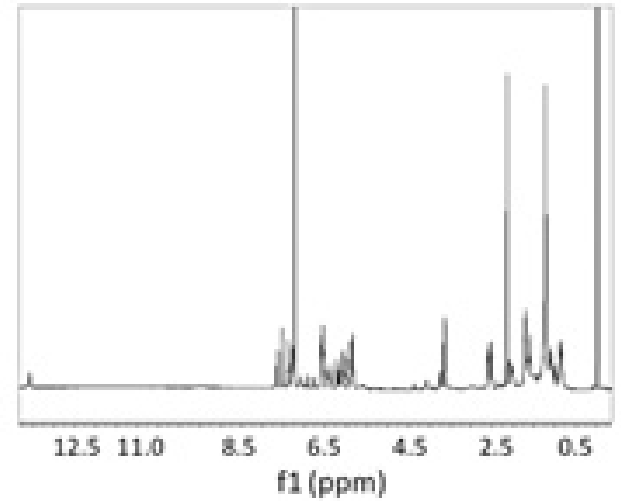

Figure 2. A typical ${ }^{1} \mathrm{H}$ NMR spectrum obtained from the samples of purified asukamycin dissolved in chloroform- $d$. Spectrum is representative of NMR analyses of four independent asukamycin samples.

of $0.5 \mathrm{mg} / \mathrm{ml}$. Following a $1 \mathrm{~h}$ incubation at $37^{\circ} \mathrm{C}$, the dark crystals formed were dissolved by adding to the wells an equal volume of SDS/DMF extraction buffer (20\% sodium dodecyl sulfate, $50 \% \mathrm{~N}, \mathrm{~N}$-dimethylformamide, $\mathrm{pH} 4.7)$. Subsequently, plates were placed overnight at $37^{\circ} \mathrm{C}$ in order to dissolve aggregates of lysed cells. Optical densities (OD) at $570 \mathrm{~nm}$ were measured by transferring $100 \mu 1$ aliquots to 96-well plates and the values were recorded using a microplate reader with the appropriate filter. Viability values in wells containing cells exposed to asukamycin were compared with the viability values from cells exposed to DMSO only. The latter values were set at $100 \%$. The baseline value for $0 \%$ cell survival was determined by lysing cells with $1 \%$ Triton X-100. Effects of the MAPK inhibitor SB 202190 were studied by adding this drug (10-50 $\mu \mathrm{M})$ to tumor cell cultures $15 \mathrm{~min}$ before asukamycin treatment.

Caspase assays. THP-1 cells were seeded into $60 \mathrm{~mm}$ tissue culture dishes (BD Falcon) at a concentration of $5 \times 10^{5}$ cells per $\mathrm{ml}$ in $6 \mathrm{ml}$ of DMEM-F12 medium containing 5\% FBS. Asukamycin $(50 \mu \mathrm{M})$ or DMSO aliquots were added and cells incubated for 24 or $72 \mathrm{~h}$. The enzymatic activity of caspases 3 and 8 was measured colorimetrically (16) using assay kits purchased from MBL International. Assays were carried out according to the instructions supplied by the manufacturer and caspase activity in cell lysates was expressed in mmol p-nitroaniline (pNA) per h per mg protein. Protein concentrations in the samples were measured by using the Bradford reagent and bovine serum albumin solutions to generate a standard curve (17).

Statistical analysis. Data are presented as means \pm standard error of the mean (SEM). The concentration-dependent effects of asukamycin and SB 202190 were evaluated statistically by the randomized blocks design analysis of variance (ANOVA). $\mathrm{P}<0.05$ was defined as statistically significant.

\section{Results}

Fig. 2 shows a typical NMR spectrum obtained from the samples of purified asukamycin dissolved in chloroform- $d$. The obtained NMR spectral characteristics were identical to

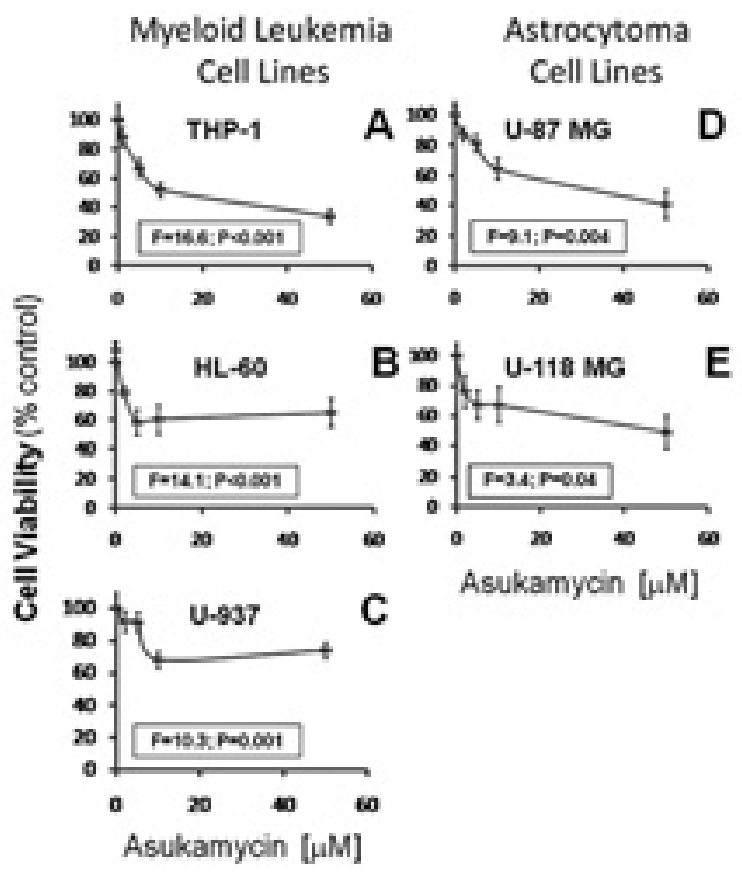

Figure 3. Asukamycin in a concentration-dependent manner reduces viability of five different human cell lines. Three myeloid leukemia cell lines THP-1 (A); HL-60 (B) and U-937 (C), and two astrocytoma cell lines U-87 MG (D) and U-118 MG (E) were exposed to various concentrations of asukamycin (1-50 $\mu \mathrm{M}$, shown on the abscissa). Cell viability was assessed after $24 \mathrm{~h}$ by the MTT assay. Data (means \pm SEM) from 4 to 10 independent experiments are expressed as \% control. Values obtained from cells exposed to DMSO only were set at $100 \%$. The concentration-dependent effects of asukamycin were evaluated by the randomized blocks design ANOVA. F- and P-values shown in the boxes are all significant.

the previously reported values (13). Beer's law and NMR analyses confirmed $>85 \%$ content of asukamycin in the purified samples.

Fig. 3 shows that asukamycin reduced viability of five different cell lines in a concentration-dependent manner (1-50 $\mu \mathrm{M})$. Although in all cases the effects were statistically significant, each of the cell lines tested had different sensitivity towards the drug. The lowest level of viability after exposure to $50 \mu \mathrm{M}$ asukamycin for $24 \mathrm{~h}$ was observed in THP-1 myelomonocytic cell cultures (Fig. 3A; 34 5 \%). Similar low levels of viability were registered in the case of U-87 MG

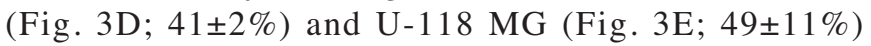
astrocytoma cells. The other two cell lines were inhibited less effectively with cell viability values of $65 \pm 10 \%$ in the case of HL-60 (Fig. 3B) and $74 \pm 6 \%$ in the case of U-937 cells (Fig. 3C). Asukamycin inhibited cell growth with $\mathrm{IC}_{50}$ values of $\sim 5 \mu \mathrm{M}$ for all cell lines tested except HL-60 cells where this value was closer to $1 \mu \mathrm{M}$ (Fig. 3B).

Next, we studied the mechanism of asukamycin-induced cell death in cultured human myelomonocytic THP-1 cells. Exposure of these cells to asukamycin $(50 \mu \mathrm{M})$ caused a significant increase in intracellular caspase 8 (Fig. 4A) and caspase 3 (Fig. 4B) activity when compared to the vehicle solution (DMSO)-treated cell cultures. Preliminary data showed that this upregulation was maximal when measured between 24 and $72 \mathrm{~h}$ after asukamycin administration. Longer incubation time did not cause the differential caspase activity to increase further (data not shown). 


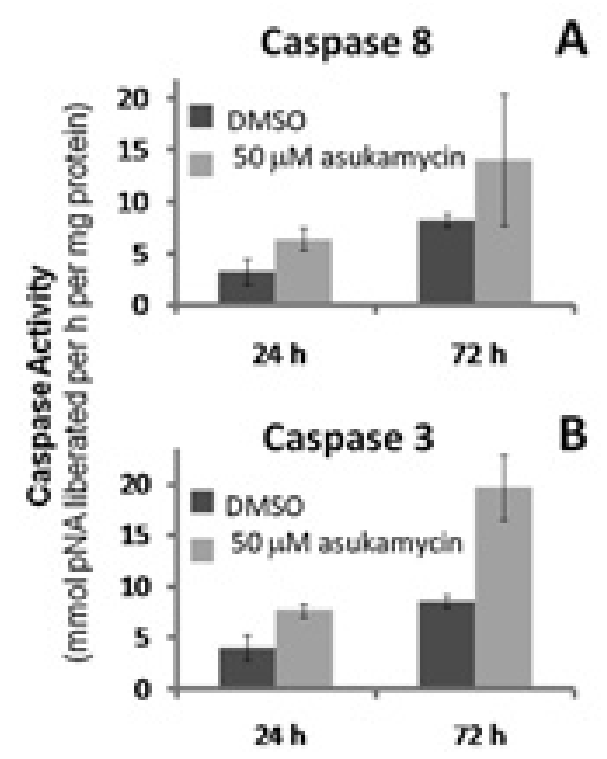

Figure 4. Asukamycin causes significant activation of caspases 3 and 8 in human THP-1 myelomonocytic cell culture. THP-1 cells $\left(3 \times 10^{6}\right)$ were exposed to $50 \mu \mathrm{M}$ asukamycin or DMSO for 24 or $72 \mathrm{~h}$. Caspase 8 (A) and caspase 3 (B) activities were measured by colorimetric assays. Data (means \pm SEM) from 3 to 6 independent experiments are expressed as mmol pNA liberated per $\mathrm{h}$ per mg protein. Statistical evaluation of the data by the randomized blocks design ANOVA indicates that the enzymatic activities of caspase 3 $(\mathrm{A}-\mathrm{F}=11.8 ; \mathrm{P}=0.01)$ and caspase $8(\mathrm{~B}-\mathrm{F}=8.7 ; \mathrm{P}=0.03)$ are significantly elevated in asukamycin-treated THP-1 cells when compared to cells exposed to the vehicle solution (DMSO) only.

Fig. 5 illustrates that SB $202190(10-50 \mu \mathrm{M})$, a selective, cell-permeable inhibitor of p38 MAPK, partially reversed the toxic action of asukamycin. In this series of experiments, incubation of THP-1 cells with $50 \mu \mathrm{M}$ asukamycin caused reduction of cell viability to $30 \pm 11 \%$ after $24 \mathrm{~h}$. Pretreatment of cells with $50 \mu \mathrm{M}$ SB 202190 reversed this value to $70 \pm 24 \%$.

\section{Discussion}

Very few studies on asukamycin have been published thus far. Most of them describe the biosynthetic pathways of this metabolite (13). Lack of a simple purification procedure and the fact that asukamycin is not available commercially could be blamed for this shortfall. Here, we describe a rapid method of isolation that uses a selective precipitation instead of the lengthy and relatively expensive chromatographic methods described earlier $(11,18)$, giving a dual advantage of decreasing the amount of time required, and making it much simpler and less expensive to scale the purification for larger fermentations. We were able to readily confirm the identity of the asukamycin by its mass, UV/Vis, and proton NMR spectra. Purity of the sample was shown to be at least $85 \%$ by chromatographic, spectrophotometric and spectrometric analyses. We tested the biological activity of four different batches of purified asukamycin. They were applied to five different human tumor cell lines including three leukemia and two astrocytoma cell lines. Asukamycin effectively reduced viability of all tumor cells tested with $\mathrm{IC}_{50}$ of $1-5 \mu \mathrm{M}$. This value is within the range of minimal inhibitory concentration (MIC) values originally reported by Omura et al (11) for the effects of asukamycin on

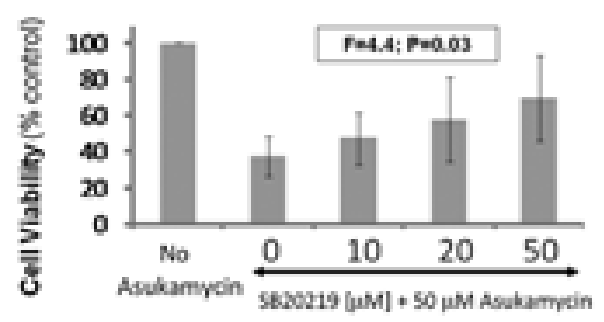

Figure 5. Asukamycin-induced toxicity in THP-1 myelomonocytic cell cultures is reduced by a specific inhibitor of p38 MAPK. THP-1 cells were pre-incubated with various concentrations (0-50 $\mu \mathrm{M}$, shown on the abscissa) of SB 202190 before their exposure to $50 \mu \mathrm{M}$ asukamycin. Cell viability was assessed after $24 \mathrm{~h}$ by the MTT assay. Data (means \pm SEM) from five independent experiments are expressed as \% control. Values obtained from cells exposed to DMSO only were set at $100 \%$. The concentrationdependent effect of SB 202190 was evaluated by the randomized blocks design ANOVA. F- and P-values are shown in the box.

various Gram-positive bacteria (1.5-45 $\mu \mathrm{M}$ range). It also corresponds well with, for example, the cytotoxic effects of manumycin A on U-937 and HL-60 myeloid leukemia cells (6) and COLO320-DM human colon tumor cells (9). Therefore, the cytotoxic activity of asukamycin, similar to that of manumycin A, is somewhat modest. Nonetheless asukamycin appears to be among the most effective antitumor agents within the manumycin-group metabolites, which generally exhibit antineoplastic activity with the $\mathrm{IC}_{50}$ values ranging from 0.5 to $50 \mu \mathrm{M}(1,4)$. It is also important to note that asukamycin has been demonstrated to have low toxicity in vivo. The $\mathrm{LD}_{50}$ for acute toxicity in mice after intraperitoneal injection was reported to be $48.5 \mathrm{mg} / \mathrm{kg}$, while up to $450 \mathrm{mg} / \mathrm{kg}$ of asukamycin caused no toxicity when administered per os (11).

While no reports on the antitumor activity of asukamycin have been published thus far, the cytotoxicity of various other manumycins has been studied in detail. Several reports indicated that this activity was due to inhibition of farnesyltransferase. Initially, Hara et al (19) demonstrated that manumycins A, B and $\mathrm{C}$ inhibit farnesyltransferase with $\mathrm{IC}_{50}$ ranging from 5 to $13 \mu \mathrm{M}$. Since farnesylation of ras proteins is crucial for development of different cancers, various inhibitors of farnesyltransferase have been studied as potential anticancer agents. Some of these drugs are already undergoing clinical trials in various solid and hematological malignancies (20).

Even though inhibition of farnesyltransferase may account for the antiproliferative effects of manumycins, recent data indicate that manumycins induce tumor cell death independently of farnesyltransferase and inhibition of ras signal transduction pathways (21). Manumycin-induced apoptosis in tumor cells has been shown by measuring various parameters including release of mitochondrial cytochrome c into the cytosol, activation of caspases 8, 9 and 3, as well as increased DNA fragmentation $(6,7,9,21,22)$. She et al (7) suggested that the cellular death induced by manumycin in human thyroid cancer cells fits the general pattern of xenobiotic-induced apoptosis, which is characterized by induction of oxidative stress, MAPK signaling (p38 MAPK in particular), release of cytochrome c and subsequent activation of the apoptotic pathways (reviewed in ref. 23). Activation of caspases 8, 9 and 3 occurs further downstream in the manumycin-induced apoptotic pathway (22). 
In this study we used the human THP-1 myelomonocytic cell line to investigate the effects of asukamycin. We demonstrated that the cytotoxic effect of asukamycin can be inhibited by SB 202190, a highly selective, cell permeable inhibitor of p38 MAPK. This kinase has already been implicated in manumycin-induced cell toxicity (7) and was shown to be a good target for the development of drugs for various cancers and leukemias $(24,25)$. Furthermore, we showed that asukamycin treatment caused significant activation of caspases 8 and 3 . These caspases have previously been shown to mediate apoptosis induced by manumycin $(7,26)$ as well as a number of other anticancer drugs $(22,25,27)$. Involvement of p38 MAPK as well as caspases 8 and 3 indicates that the cytotoxic action of asukamycin is mediated by pathways that are very similar to those described for the effect of manumycin, and a combination of manumycin with paclitaxel, on thyroid cancer cells $(7,22)$ as well as for the effects of auranofin on HL-60 leukemia cells (25). In the latter study, p38 MAPK was shown to activate both the extrinsic and intrinsic apoptotic pathways (28) that resulted in parallel processes of caspase 8 activation and cytochrome c release, both of which lead to downstream activation of caspase 3 .

In summary, we developed a rapid and scalable new technique that can be used to obtain large quantities of asukamycin from cultures of Streptomyces nodosus subspecies asukaensis. We demonstrate that this manumycin-group metabolite possesses moderate antitumor activity, which is associated with activation of caspases 8 and 3 and involves p38 MAPK signalling. Similar pathways have already been implicated in the case of cytotoxic activity of manumycins and other antineoplastic agents. Due to the low in vivo toxicity of asukamycin reported earlier, further studies of asukamycin as a potential antitumor agent are warranted.

\section{Acknowledgements}

This work was supported by grants from the Natural Sciences and Engineering Research Council (NSERC) of Canada, Irving K. Barber School of Arts and Sciences (UBC Okanagan) and the Jack Brown and Family AD Research Fund.

\section{References}

1. Sattler I, Thiericke R and Zeeck A: The manumycin-group metabolites. Nat Prod Rep 15: 221-240, 1998.

2. Sugita M, Sugita $H$ and Kaneki M: Farnesyltransferase inhibitor, manumycin A, prevents atherosclerosis development and reduces oxidative stress in apolipoprotein E-deficient mice. Aterioscler Thromb Vasc Biol 27: 1390-1395, 2007.

3. Bernier M, Kwon YK, Pandey SK, et al: Binding of manumycin A inhibits IкB kinase $B$ activity. J Biol Chem 281: 2551-2561, 2006.

4. Kohno J, Nishio M, Kawano K, et al: TMC-1 A, B, C and D, new antibiotics of the manumycin group produced by Streptomyces $\mathrm{sp}$ Taxonomy, production, isolation, physico-chemical properties, structure elucidation and biological properties. J Antibiot 46: 1212-1220, 1996.

5. Zeeck A, Schröder K, Frobel K, Grote R and Thiericke R: The structure of manumycin. I. Characterization, structure elucidation and biological activity. J Antibiot 40: 1530-1540, 1987.

6. She M, Pan J, Sun L and Yeung SC: Enhancement of manumycin A-induced apoptosis by methoxyamine in myeloid leukemia cells. Leukemia 19: 595-602, 2005.
7. She M, Yang H, Sun L and Yeung SC: Redox control of manumycin A-induced apoptosis in anaplastic thyroid cancer cells: involvement of the xenobiotic apoptotic pathway. Cancer Biol Ther 5: 275-280, 2006.

8. Shu YZ, Huang S, Wang RR, et al: Manumycins E, F and G, new members of manumycin class antibiotics from Streptomyces sp. J Antibiot 47: 324-333, 1994.

9. Di Paolo A, Danesi R, Nardini D, et al: Manumycin inhibits ras signal transduction pathway and induces apoptosis in COLO320-DM human colon tumour cells. Br J Cancer 82: 905-912, 2000.

10. Zhou JM, Zhu XF, Pan QC, Liao DF, Li ZM and Liu ZC: Manumycin induces apoptosis in human hepatocellular carcinoma HepG2 cells. Int J Mol Med 12: 955-959, 2003.

11. Omura S, Kitao C, Tanaka H, Oiwa R and Takahashi Y: A new antibiotic, asukamycin, produced by Streptomyces. J Antibiot 29: 876-881, 1976.

12. Hu YD and Floss HG: Further studies on the biosynthesis of the manumycin-type antibiotic, asukamycin, and the chemical synthesis of protoasukamycin. J Am Chem Soc 126: 3837-3844, 2004.

13. Cho H, Sattler I, Beale JM, Zeeck A and Floss HG: Some aspects of the stereochemistry and biosynthesis of asukamycin. J Org Chem 58: 7925-7928, 1993.

14. Hansen MB, Nielsen SE and Berg K: Re-examination and further development of a precise and rapid dye method for measuring cell growth/cell kill. J Immunol Methods 119: 203-210, 1989.

15. Klegeris A and McGeer PL: Chymotrypsin-like proteases contribute to human monocytic THP-1 cell as well as human microglial neurotoxicity. Glia 51: 56-64, 2005.

16. Gurtu V, Kain SR and Zhang G: Fluorometric and colorimetric detection of caspase activity associated with apoptosis. Anal Biochem 251: 98-102, 1997.

17. Bradford M: A rapid and sensitive method for the quantitation of microgram quantities of protein utilizing the principle of dyebinding. Anal Biochem 72: 248-254, 1976.

18. Thiericke R, Zeeck A, Nakagawa A, et al: Biosynthesis of the manumycin group antibiotics. J Am Chem Soc 112: 3979-3987, 1990.

19. Hara M, Akasaka K, Akinaga S, et al: Identification of Ras farnesyltransferase inhibitors by microbial screening. Proc Natl Acad Sci USA 90: 2281-2285, 1993.

20. Mazieres J, Pradines A and Favre G: Perspectives on farnesyltransferase inhibitors in cancer therapy. Cancer Lett 206: 159-167, 2004.

21. Sears KT, Daino H and Carey GB: Reactive oxygen speciesdependent destruction of MEK and Akt in manumycin stimulated death of lymphoid tumor and myeloma cell lines. Int J Cancer 122: 1496-1505, 2008.

22. Pan J, Xu G and Yeung SC: Cytochrome c release is upstream to activation of caspase- 9 , caspase- 8 , and caspase- 3 in the enhanced apoptosis of anaplastic thyroid cancer cells induced by manumycin and paclitaxel. J Clin Endocrinol Metab 86: 4731-4740, 2001.

23. Cohen GM: Caspases: the executioners of apoptosis. Biochem $\mathrm{J}$ 326: 1-16, 1997.

24. Chiacchiera F and Simone C: Signal-dependent regulation of gene expression as a target for cancer treatment: inhibiting $\mathrm{p} 38 \alpha$ in colorectal tumors. Cancer Lett 265: 16-26, 2008.

25. Park SJ and Kim IS: The role of p38 MAPK activation in auranofin-induced apoptosis of human promyelocytic leukaemia HL-60 cells. Br J Pharmacol 146: 506-513, 2005.

26. Frassanito MA, Mastromauro L, Cusmai A and Dammacco F: Blockade of the Ras pathway by manumycin, a farnesyltransferase inhibitor, overcomes the resistance of myeloma plasma cells to Fas-induced apoptosis. Clin Exp Med 4: 174$182,2005$.

27. Ferrari D, Stepczynska A, Los M, Wesselborg S and SchulzeOsthoff K: Differential regulation and ATP requirement for caspase- 8 and caspase- 3 activation during CD95- and anticancer drug-induced apoptosis. J Exp Med 188: 979-984, 1998.

28. Fulda S and Debatin KM: Extrinsic versus intrinsic apoptosis pathways in anticancer chemotherapy. Oncogene 25: 4798-4811, 2006. 